\title{
The Changes of the Expression of PGC-1 $\alpha$ and the Level of Oxidative Stress in NAFLD as well as the Effects of Metformin on NAFLD
}

\author{
Jian-hua Jiang*, Jing Cheng, Bao Zhang, Shi-xia Guan and Li-li Hou \\ Department of Clinical Nutriology, the First Affiliated Hospital of Anhui Medical University, Hefei, China
}

\begin{abstract}
Purpose: The objective of this study was to determine how metformin regulates the major activator of hepatic

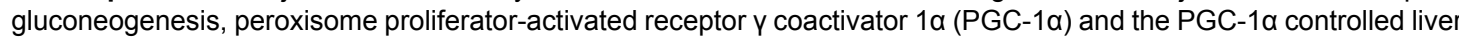
functions.

Methods: In population study, we selected 40-69 years old patients with NAFLD, 77, and 102 healthy subjects as a control group. We detect the levels of serum PGC-1a, MDA and the activity of SOD of the two groups. In vitro study, L-02 cells were treated by $20 \mu \mathrm{g} / \mathrm{ml}$ oleic acid to induce the NAFLD cells model. The control group added ordinary 1640 culture medium. The model group cells were cultured in the medium containing $2.5,5,7.5 \mathrm{mmol} / \mathrm{l}$ concentrations of metformin. Used RT-PCR analysis of PGC-1a mRNA, detected the level of triglycerides in cells, measured the content of MDA and the activity of SOD.

Results: In population study, the level of MDA in the case group were increased obviously and the activity of SOD was decreased compared with the control group. There had no difference of the level of PGC-1 $1 \alpha$ between the two groups. In vitro study, compared with the control groups, the level of triglyceride and the concentration of MDA in the model groups were increased and the activity of SOD as well as the expression of PGC-1 $\alpha$ mRNA were decreased; When the final concentration of metformin is $7.5 \mathrm{mmol} / \mathrm{l}$, the level of triglyceride and MDA were decreased as well as the activity of SOD and the expression of PGC-1a mRNA were increased compared with the model group.

Conclusion: Metformin can adjust the expression of PGC-1 $\alpha$ and the level of oxidative stress which can decrease the fat accumulation, Our results thus identify selective modulation of hepatic PGC-1 $\alpha$ functions as a novel mechanism involved in the therapeutic action of metformin.

Keywords: Nonalcoholic fatty liver; PGC-1 $\alpha$; MDA; SOD; Metformin

\section{Introduction}

With the improvement of people's living standard and the change of lifestyle as well as population aging, the incidence of non-alcoholic fatty liver disease (NAFLD) in China is increasing gradually [1-3]. Nonalcoholic steatohepatitis(NASH) is the main stagein the progression of NAFLD, which can also lead to liver cirrhosis [4] even hepatocellular carcinoma [5]. In addition, NAFLD is associated with increased risk of inflammation, cardiovascular disease [6,7] as well as insulin resistance (IR) and type 2 diabetes [8]. Although the pathogenesis of NAFLD is not clearly understood, it is known that insulin resistance assumes a pivotal role and it is generally regarded as the hepatic component of the metabolic syndrome (MetS) [9]. However, there is no accepted standard medication in the treatment of NAFLD. But drugs which can improve insulin sensitivity are widely used because insulin resistance play an important role in the pathophysiology of NAFLD [10]. A open label trial in well-characterized patients with NASH, metformin therapy was associated with improvements in insulin sensitivity in most patients and with weight loss, decreases in serum aminotransferase levels and improvements in liver histology in approximately $30 \%$ of patients [11]. Metformin is a biguanide drug that improves insulin sensitivity in the liver and skeletal muscle [12]. Metformin is known to stimulate AMPactivated protein kinase (AMPK) activity in primary hepatocytes, a hepatoma cell line and in whole liver [13-15]. Researchers describing the possible mechanisms by which metformin or other AMPK activators regulate the expression of genes for gluconeogenesis through AMPK [16]. The exact mechanisms of action are not fully understood, but probably involve the activation of AMPK, which results in the suppression of the production of glucose [17], cholesterol, and triglycerides, and stimulation of fatty acid oxidation [18].

Peroxisome proliferator activated receptor $\gamma$ coactivator $1 a$ (PGC-1 $\alpha$ ) is a regulator of myocardial energy metabolism and mitochondrial biogenesis $[19,20]$. PGC-1 $\alpha$ can regulate mitochondrial antioxidant enzyme's activity and expression in brain tissues [21] and cultured vascular endothelial cells [22]. The expression of mitochondrial antioxidants including superoxide dismutase 2 (SOD2) and uncoupling protein 2 (UCP2) were reduced and had a increased vulnerability to oxidative injury of the dopaminergic neurons in the brain tissue of PGC-1 $\alpha$ null mice [21]. Overexpression of PGC-1 $\alpha$ in vascular endothelial cells increased mitochondrial antioxidant enzyme expression, and decreased oxidative stress and cell death [22]. In liver, PGC-1a stimulates gluconeogenesis, fatty acid oxidation and heme biosynthesis [23]. Because PGC-1 1 has been shown to play an important role in regulation of gluconeogenesis, it has also been suggested to be involved in the hepatic action of metformin [24]. Although PGC-1a is a key regulator of energy metabolism, the effects of metformin on hepatic PGC-1 $\alpha$ expression and function have not been specifically studied. Thus, it appears timely to intensify research on metformin in the context of NAFLD and to begin delineating cellular and molecular events that may be activated beneficially in liver. Therefore, the aim of this study was to evaluate the effects of metformin on important phenotypic modifiers in NAFLD.

*Corresponding author: JIANG Jian-hua, Department of Clinical Nutriology, the First Affiliated Hospital of Anhui Medical University, No.218 Jixi Road, Hefei, Anhui Province 230032, China, Tel: +86 0551 62923751; E-mail: jhua@yeah.net

Received November 19, 2015; Accepted December 22, 2015; Published December 29, 2015

Citation: Jiang JH, Cheng J, Zhang B, Guan SX, Hou LI (2015) The Changes of the Expression of PGC-1 $\alpha$ and the Level of Oxidative Stress in NAFLD as well as the Effects of Metformin on NAFLD. J Metabolic Synd 5: 193. doi:10.4172/21670943.1000193

Copyright: $\odot 2015$ Jiang JH, et al. This is an open-access article distributed under the terms of the Creative Commons Attribution License, which permits unrestricted use, distribution, and reproduction in any medium, provided the original author and source are credited. 


\section{Materials and Methods}

\section{Population study}

Subjects: All patients with clinical and evidence of NAFLD were selected from July to November 2012 at the medical center of the First Affiliated Hospital of Anhui Medical University. 77 patients and 102 normal population aged 40-69 years old were selected, there had no statistically significant differences in the constitute of age and gender between the two groups. Health questionnaires including general demographic characteristics, lifestyle, disease history were performed in all objects. Inclusion criteria were: patients without alcohol use or occasional use $(<30 \mathrm{gr}$ alcohol per day in men, and $<20$ grains in women). Results of liver ultrasound study meet the diagnostic criteria of mild diffuse fatty liver and cannot be explained by other reasons. Exclusion criteria were: chronic hepatic disease (hepatitis B and C, hemochromatosis), systemic comorbidities and neoplasm, hepatotoxic drugs during the past 6 months [25]. Subjects had to keep on an empty stomach more than 12 hours, and not taking lipid-lowering drugs, high-fat foods and alcohol within the 24 hours. This study was approved by the ethics committees. Informed consent was obtained from all patients.

\section{Methods}

Ultrasonic testing: All subjects were received the examination of liver ultrasound (by Toshiba 660, Japan) in the same condition. To avoid inter-operator discordance, we used an expert radiologist performed ultrasonic evaluations for all the subjects and repeated the suspicious ultrasonographies.

The determination of biochemical indicators: peripheral venous blood were collected on an empty stomach, we used automatic biochemical analyzer (by Hitachi - 7600, Japan) test fasting blood glucose (FBG), total cholesterol (TC), triglyceride (TG), very low density lipoprotein (VLDL -c), high-density lipoprotein (HDL - C), low density lipoprotein (LDL - C) and uric acid (UA), biochemical reagents bought from Roche Co., Ltd.

Determination of PGC-1a level in serum: Using ELISA method (PGC-1 $\alpha$ ELISA kit was purchased from beijing biotechnology research institute, China), first to join the standard and sample to be tested, set up the negative control, under the condition of $37^{\circ} \mathrm{C}$ reacting $30 \mathrm{~min}$, washing board for four times, adding enzyme reagent, under the condition of $37^{\circ} \mathrm{C}$ reacting $30 \mathrm{~min}$, washing board for four times, adding color reagent $\mathrm{A}$ and $\mathrm{B}$, under the condition of $37^{\circ} \mathrm{C}$ coloring 15 $\mathrm{min}$, then join the terminated reagent, the absorbance $(\mathrm{A})$ values were measured at $450 \mathrm{~nm}$, finally, draw the standard curve and calculate the concentration of PGC-1 $\alpha$.

The determination of the level of MDA and the activity of SOD in serum: All subjects were not take antioxidants within a month, all subjects were collected $4 \mathrm{~m} 1$ venous blood on an empty stomach, centrifuged the blood at a room temperature $(2500 \mathrm{r} / \mathrm{min}, 8 \mathrm{~min})$, serum was separated and placed in a $20^{\circ} \mathrm{C}$ cryopreservation. The level of MDA in the serum were measured by thiobarbituric acid method (TBA), the determination of SOD was by xanthine oxidation method (XTO) (the kits above were purchased from Nanjing Jiancheng biological reagent company, China). One unit SOD is defined as the amount of the protein that inhibitis the rate of NBT reduction by $50 \%(\mathrm{U} / \mathrm{ml})$

\section{Vitro study}

Materials and cells: The human normal hepatocyte cell line L-02 was purchased from the cell bank of the Institute of Biochemistry and Cell Biology (Shanghai, China). RPMI 1640 medium without sugar and phenol (were purchased from Gibco BRL Co. Ltd. USA); fetal calf serum ( HyClone, Logan, UT, USA); 1:125 trypsin ( Gibco, USA); streptomycin, penicillin(China Pharmaceutical Husheng Co. Ltd.); metformin (Sigma, USA); TG test kit, Malonyldialdehyde (MDA) and superoxide dismutase (SOD) assay kits were obtained from Nanjing Jiancheng biological reagent company, China. BCA protein assay kit (Biocolor Bioscience \& Technology Com-pany). TRIzol PrimeScript RT reagent kit and T SYBR Premix Ex Taq ${ }^{\prime \prime}$ kit (Takara Biotechnology Co., Ltd.).

Experimental protocols: The L-02 cells were cultured in RPMI 1640 medium supplemented with $10 \%$ heat-inactivated fetal calf serum and $1 \% \mathrm{v} / \mathrm{v}$ penicillin/streptomycin in a $5 \% \mathrm{CO} 2$ humidified atmosphere at $37^{\circ} \mathrm{C}$. According to the methods from literatures [26], the L02 cells were grown to $80 \%$ confluence added $20 \mu \mathrm{g} / \mathrm{ml}$ oleic acid (dissolved by $0.5 \%$ DMSO) into the medium for $24 \mathrm{~h}$ to induce the cell model of nonalcoholic fatty liver disease. The control group added ordinary 1640 culture medium containing $10 \%$ fetal calf serum. The cells of the model group were cultured in the medium containing 2.5, $5,7.5 \mathrm{mmol} / \mathrm{l}$ concentrations of metformin which were marked group $1,2,3$ and continue to cultivate 24 hour then collected cells. There were five replicates in each group.

The evaluation of the non-alcoholic fatty liver cells model: Cells were treated by oleic acid for 24 hours, collected cells by the digestion of trypsin and then observed under the electron microscope. Have a biochemical detection of intracellular triglyceride of each groups.

Determination of intracellular triglyceride: About $1 \times 105$ cells were implanted in each hole of the 6 hole plate. The supernatant was discarded after packet processing, then collected the cells in each cell culture plate and frozen- thawed the cells repeatedly, After centrifugation for $5 \mathrm{~min}$ at 3,000 rpm the decanted supernatant was saved as the TG extract. Using TG test kit(Nanjing Jincheng Corp, China)to detect the contents of TG. Take the remaining liquid for the quantitation of proteins, the protein content was measured using a BCA protein assay.

Assay for intracellular contents of SOD and MDA: The culture medium was collected, then cells were washed with D-Hanks, scraped from the plates into $1 \mathrm{ml}$ of icecold PBS $(0.1 \mathrm{M}$, containing $0.05 \mathrm{mM}$ of EDTA), and homogenized. The homogenate was centrifuged at $4000 \mathrm{r} /$ min for 10 minutes at $4{ }^{\circ} \mathrm{C}$, the MDA contents and SOD activities in the supernatant were measured by the assay kit (Nanjing Jincheng Corp, China) according to its provider's instructions. The activities of SOD were expressed as units per milligram protein. MDA was measured at a wavelength of $532 \mathrm{~nm}$ by reacting with thiobarbituric acid to form a stable chromophoric production. Values of MDA level were expressed as nanomoles per milligram protein.

The measurement of the expression of PGC-1a mRNA by RT-PCR: The total RNA of cells was extracted using TRIzol reagent and cDNA was synthesized according to the instructions from the PrimeScript ${ }^{\circ}$ RT reagent kit. RT-PCR primers were as follows: Upstream of PGC-1 $\alpha$ : CAGCAAGTCCTCAGTCCTCAC; downstream of PGC-1a: TGCCTCCAAAGTCTCTCTCAG; product size:247bp. Upstream of $\beta$-action: GAAATGGAGGCACCCCTTC; downstream of $\beta$-action:TTGCCGACAGGATGCAGAA; product size:100bp.The reaction system was prepared according to the instructions of the SYBR $^{\circ}$ Premix Ex Taq ${ }^{\mathrm{m}}$ kit and then DNA was amplified as follows: $95^{\circ} \mathrm{C}$ for 10 minutes; then $95^{\circ} \mathrm{C}$ for $15 \mathrm{sec}, 61^{\circ} \mathrm{C}$ for $15 \mathrm{sec}$ and $72^{\circ} \mathrm{C}$ for $15 \mathrm{sec}$ for $40 \mathrm{cycles}$; and finally $95^{\circ} \mathrm{C}$ for 1 minutes, $55^{\circ} \mathrm{C}$ for 30 secponds and $95^{\circ} \mathrm{C}$ for $30 \mathrm{sec}$. PCR products were electrophoresed in agarose gel, to determine the expression of target and reference gene. 
Citation: Jiang JH, Cheng J, Zhang B, Guan SX, Hou LI (2015) The Changes of the Expression of PGC-1a and the Level of Oxidative Stress in NAFLD as well as the Effects of Metformin on NAFLD. J Metabolic Synd 5: 193. doi:10.4172/2167-0943.1000193

Page 3 of 6

Observed under the electron microscope: The fixation and treating of cells as well as sections were made by professionals from Electron Microscopy Room in Anhui Provincial Hospital (In Anhui province of China). Observing organelles structures, mitochondria and lipid droplet under the electron microscope.

\section{Statistical analysis:}

The continuous variables were summarized by the mean and range. Other categorical variables were summarized by count and percentage. The SPSS Statistics 15.0 package was utilized to analyze the data. Spearman rank correlation coefficients were used to summarize monotonic relationships between PGC-1 $\alpha$ and triglyceride, MDA, SOD in cells. Differences among groups were analyzed using the oneway analysis of variance (ANOVA), followed by multiple comparisons by LSD test. The $\mathrm{p}<0.05$ was considered statistically significant.

\section{Results}

\section{Population study}

Baseline characteristics: There had no difference of the age, sex and blood pressure between the two groups; Compared with the control group, BMI in the case group was increased obviously, and the difference was statistically significant $(\mathrm{p}<0.05)$ (Table 1$)$.

The comparison of biochemical indicators: Compared with the control group, the level of TC, TG, VLDL-C, LDL-C , FBG, UA and ALT in the case group were increased obviously, and the level of HDL in the case group was decreased, the differences were statistically significant $(\mathrm{p}<0.05)$. There had no difference of the level of AST between the two groups (Table 2).

The comparison of the level of PGC-1 $\alpha$ MDA and the activity of SOD in serum: Compared with the control group, the level of MDA in the case group were increased obviously, and the vitality of SOD in the case group was decreased, the differences were statistically significant $(p<0.05)$. There had no difference of the level of PGC- $1 \alpha$ between the two groups (Table 3 ).

\section{In vitro study}

The structure of organelles under the electron microscope: Many mitochondria can be seen in cells of control group, their shape is elliptical or round, and the membrane and carinulae of mitochondria were clear. In the model group, the number of mitochondria was decreased apparently. The membrane and inner carinulae in deformed mitochondria were absent, most of mitochondrions changed to vacuole after the cells exposed to oleic acid (the level of intracellular triglyceride by biochemical detection showed that an increasing level in model group, it indicated that we successfully built up NAFLD cells model). In the cells of Group1 (metformin $2.5 \mathrm{mmol} / \mathrm{l}$ ) and Group 2 (metformin $5 \mathrm{mmol} / \mathrm{l}$ ), the vacuolation of mitochondria decreased. In the cells of Group3 (metformin $7.5 \mathrm{mmol} / \mathrm{l}$ ), the mitochondria were a little swelling, but the membrane and carinulae of mitochondria were clear and with an obvious reduction of vacuolation (Figure 1).

\section{The effect of metformin on the level of triglyceride in L-02 cells}

Compared with the control group, the level of triglyceride in the cells of the model group increased obviously, and the difference was statistically significant $(\mathrm{p}<0.05)$. When the final concentration of metformin is $7.5 \mathrm{mmol} / \mathrm{l}$, the level of triglyceride decreased compared with the model group and the difference was statistically significant $(\mathrm{p}<0.05)$. The level of triglyceride in the Group3 (metformin $7.5 \mathrm{mmol} / \mathrm{l}$ ) decreased compared with Group1 (metformin $2.5 \mathrm{mmol} / \mathrm{l}$ ), the difference was statistically significant $(\mathrm{p}<0.05)$ (Figure 2$)$.
The effect of metformin on the level of MDA and the activity of SOD in cells

Compared with the control group, the concentration of MDA was increased apparently with a difference of statistical significance $(p<0.05)$, and the vitality of SOD is reduced significantly, the difference was statistically significant $(\mathrm{p}<0.05)$. Compared with the model group, when the final concentration of metformin is $5 \mathrm{mmol} / \mathrm{l}, 7.5 \mathrm{mmol} / \mathrm{l}$, the concentration of MDA was decreased apparently with a difference of statistical significance $(\mathrm{p}<0.05)$, and the activity of SOD is increased significantly, the difference was statistically significant $(\mathrm{p}<0.05)$

\begin{tabular}{|cccc|}
\hline Variable & Case group $(\mathbf{n}=\mathbf{7 7})$ & Control group $(\mathbf{n = 1 0 2})$ & p value \\
\hline Age $($ years $)$ & $47.40 \pm 6.79$ & $49.13 \pm 7.83$ & $>0.05$ \\
Male, $\mathrm{n}(\%)$ & $47(61.0)$ & $62(60.8)$ & $>0.05$ \\
SBP $(\mathrm{mmHg})$ & $121.63 \pm 10.67$ & $119.42 \pm 9.21$ & $>0.05$ \\
DBP $(\mathrm{mmHg})$ & $75.54 \pm 8.16$ & $73.26 \pm 7.89$ & $>0.05$ \\
BMI $\left(\mathrm{kg} / \mathrm{m}^{2}\right)$ & $25.52 \pm 4.59$ & $22.0 \pm 2.36$ & $<0.001$ \\
\hline
\end{tabular}

Table 1: Baseline characteristics (age 40-69) of the NAFLD case and control populations.

\begin{tabular}{|c|c|c|c|}
\hline Variable & Case group $(\mathbf{n}=\mathbf{7 7})$ & Control group $(\mathbf{n = 1 0 2})$ & p value \\
\hline TC $(\mathrm{mmol} / \mathrm{L})$ & $5.10 \pm 1.02$ & $4.48 \pm 0.69$ & $<0.001$ \\
\hline TG $(\mathrm{mmol} / \mathrm{L})$ & $2.03 \pm 1.09$ & $1.16 \pm 0.52$ & $<0.001$ \\
\hline HDL-C $(\mathrm{mmol} / \mathrm{L})$ & $1.15 \pm 0.27$ & $1.36 \pm 0.31$ & $<0.001$ \\
\hline VLDL-C $(\mathrm{mmol} / \mathrm{L})$ & $0.75 \pm 0.40$ & $0.43 \pm 0.19$ & $<0.001$ \\
\hline LDL-C $(\mathrm{mmol} / \mathrm{L})$ & $3.19 \pm 0.97$ & $2.69 \pm 0.65$ & $<0.001$ \\
\hline FBG $(\mathrm{mmol} / \mathrm{L})$ & $5.18 \pm 0.40$ & $4.63 \pm 1.10$ & $<0.001$ \\
\hline UA $(\mu \mathrm{mol} / \mathrm{L})$ & $356.34 \pm 70.34$ & $305.37 \pm 76.91$ & $<0.001$ \\
\hline ALT(IU/L) & $28.08 \pm 14.13$ & $18.64 \pm 8.10$ & $<0.001$ \\
\hline AST(IU/L) & $20.51 \pm 5.95$ & $19.23 \pm 5.03$ & $>0.05$ \\
\hline
\end{tabular}

Table 2: Biochemical indicators.

\begin{tabular}{cccc} 
Variable & Case group $(\mathbf{n = 7 7})$ & Control group $(\mathbf{n = 1 0 2})$ & $\mathbf{p}$ value \\
\hline PGC-1 $\alpha(\mathrm{nmol} / \mathrm{L})$ & $25.76 \pm 8.00$ & $24.28 \pm 6.14$ & $>0.05$ \\
SOD $(\mathrm{U} / \mathrm{ml})$ & $75.65 \pm 6.35$ & $98.19 \pm 7.03$ & $<0.001$ \\
MDA $(\mu \mathrm{mol} / \mathrm{L})$ & $5.08 \pm 0.42$ & $3.85 \pm 0.36$ & $>0.001$
\end{tabular}

Table 3: The level of PGC-1a MDA and the vitality of SOD in serum.
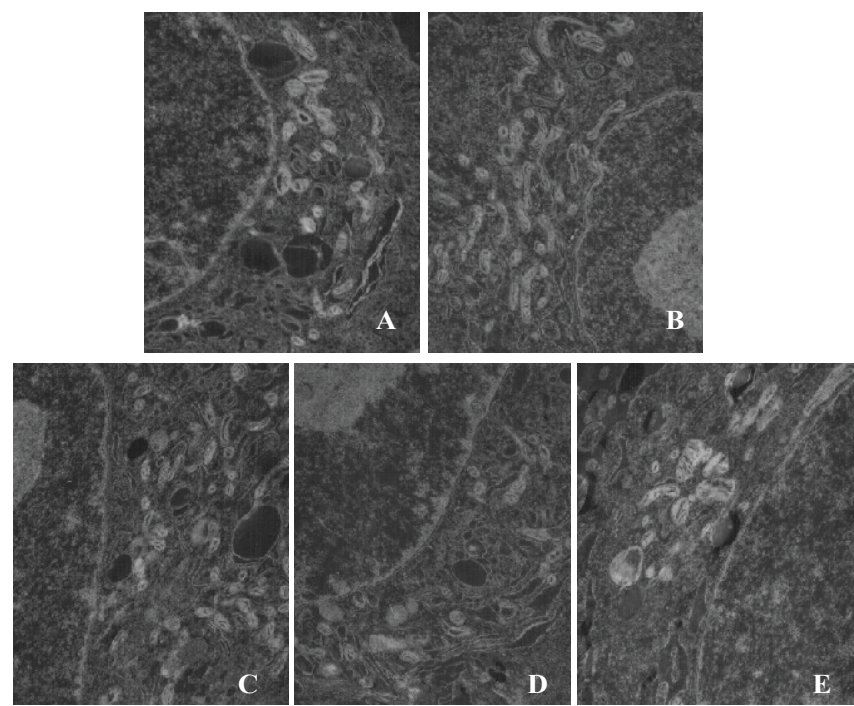

(A: the model group; B: the control group; C: the low dose of metformin; $D$ : the medium dose of metformin; $\mathrm{E}$ : the high dose of metformin.)

Figure 1: The changes in electron microscope of L-02 cells. 
Compared with the final concentration of metformin was $2.5 \mathrm{mmol} / \mathrm{l}$ group, when the final concentration of metformin was respectively $5 \mathrm{mmol} / \mathrm{l}, 7.5 \mathrm{mmol} / \mathrm{l}$, the concentration of $\mathrm{MDA}$ was reduced apparently with a difference of statistical significance $(\mathrm{p}<0.05)$, and the vitality of SOD is increased significantly, the difference was statistically significant $(\mathrm{p}<0.05)$ (Figures 3 and 4$)$.

The effect of metformin on the expression of PGC-1a mRNA in L-02 cells

Compared with the control group, the expression of PGC-1 $\alpha$ mRNA in L-02 cells in model group decreased apparently with a difference of statistical significance $(\mathrm{p}<0.05)$. Compared with the model group, when the final concentration of metformin was respectively $2.5 \mathrm{mmol} /$ 1,Group1), $5 \mathrm{mmol} / \mathrm{l}$, Group2), $7.5 \mathrm{mmol} / \mathrm{l}$, Group3), the expression of PGC-1 $\alpha$ mRNA in L-02 cells were increased obviously and with a differences of statistical significance $(\mathrm{p}<0.05)$. The expression of PGC1a mRNA in Group3 was higher than that in Group1 with a difference of statistical significance $(\mathrm{p}<0.05)$ (Figures 5 and 6).

\section{Correlation}

The expression of PGC-1 1 mRNA showed a negative correlation with the levels of triglyceride and the concentration of MDA in L-02

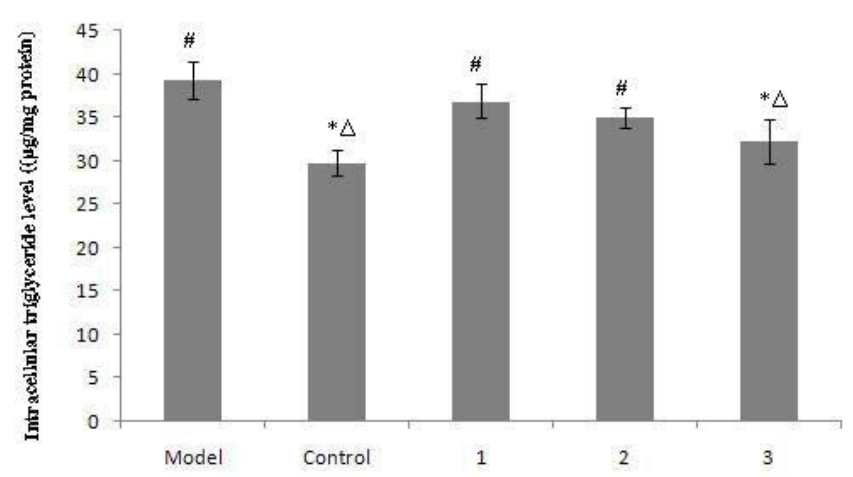

(Model: the model group; Control: the control group; 1: the low dose of metformin; 2 : the medium dose of metformin; 3 : the high dose of metformin.) Compared with the model group, ${ }^{*} p<0.05$; Compared with the control group, ${ }^{\#} \mathrm{p}<0.05$; Compared with the first group, ${ }^{*} \mathrm{p}<0.05$.

Figure 2: The content of intracellular triglyceride in $\mathrm{L}-02$ cells $(\mu \mathrm{g} / \mathrm{mg}$ protein).

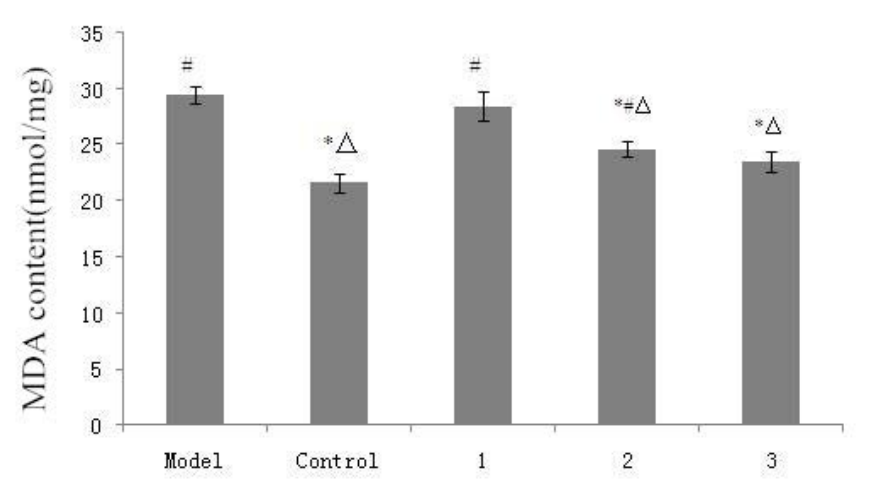

(Model: the model group; Control: the control group; 1: the low dose of metformin; 2: the medium dose of metformin; 3 : the high dose of metformin.) Compared with the model group, " $p<0.05$; Compared with the control group, ${ }^{\#} p<0.05$; Compared with the first group, $" \mathrm{p}<0.05$.

Figure 3: The concentration of MDA in cells.

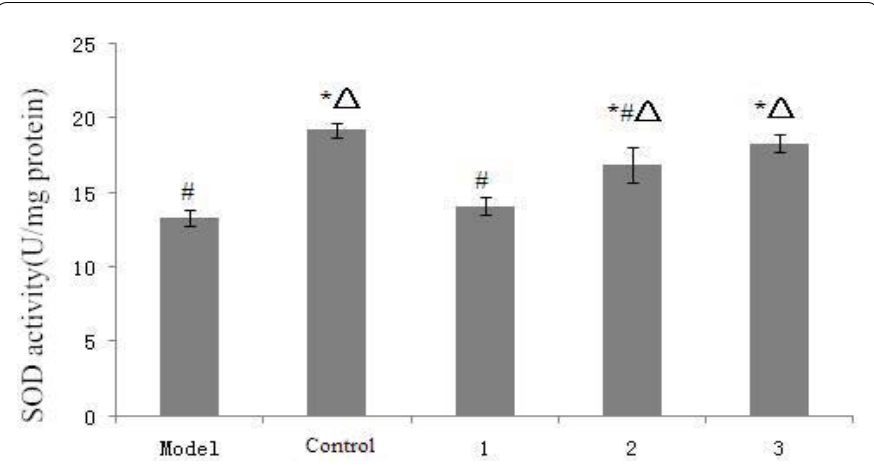

(Model: the model group; Control: the control group; 1: the low dose of metformin; 2: the medium dose of metformin; 3 : the high dose of metformin.) Compared with the model group, " $p<0.05$; Compared with the control group, ${ }^{\#} \mathrm{p}<0.05$; Compared with the first group, ${ }^{*} p<0.05$.

Figure 4: The activity of SOD in cells.

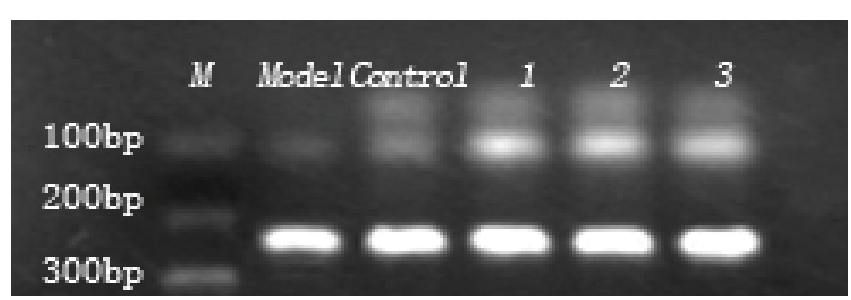

(Model: the model group; Control: the control group; 1: the low dose of metformin; 2: the medium dose of metformin; 3: the high dose of metformin; M: DNA marker.)

Figure 5: The expression of PGC-1 a mRNA.

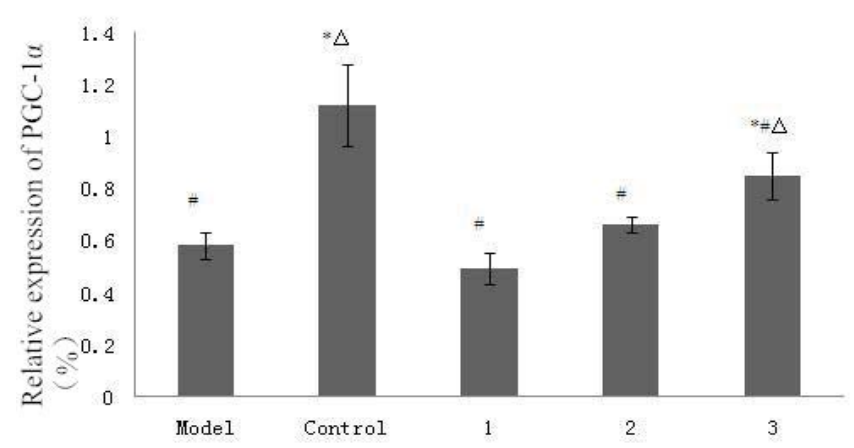

(Model: the model group; Control: the control group; 1: the low dose of metformin; 2 : the medium dose of metformin; 3 : the high dose of metformin.) Compared with the model group, " $p<0.05$; Compared with the control group, ${ }^{\#} \mathrm{p}<0.05$; Compared with the first group, ${ }^{*} \mathrm{p}<0.05$

Figure 6: The expression of PGC-1 a mRNA.

cells $(r=-0.581,-0.629, p<0.05)$; the expression of PGC- $1 \alpha$ mRNA showed a positive correlation with the activity of SOD in L-02 cells $(\mathrm{r}=0.746, \mathrm{p}<0.05)$.

\section{Discussion}

PGC-1a regulates mitochondrial biogenesis and function, oxidative stress, gluconeogenesis, and lipogenesis, all of which are key factors in the development of NAFLD [27]. PGC-1 $\alpha$ interacts with different transcription factors and activates distinct biological programs in different tissues, including gluconeogenesis in the liver, 
thermogenesis in brown fat, and angiogenesis in skeletal muscles [28]. In hepatocytes, PGC-1 $\alpha$ orchestrates broad energy programs, including gluconeogenesis and mitochondrial fatty acid $\beta$-oxidation [29]. As IR is closely related to the pathogenesis of NAFLD, there had a study founded that mild and long-term decreased expression of PGC$1 \alpha$ is one of the reasons causing IR in mice liver [30]. However, Koo et al. [31] demonstrated that a sharp, adenoviral-mediated reduction of hepatic PGC-1a increased insulin sensitivity in vivo. In our population study, there had no difference of the level of PGC-1a between the case group and control group. However, the expression of PGC-1a mRNA in the cells of the model group was decreased apparently compared with the control group in our vitro study. The reason of this result may be due to the complexity of human body system and the difference of the detection method, but by vitro experiments we concluded that the decrease of the expression of PGC-1 $\alpha$ may play an important role in the pathogenesis of NAFLD.

Oxidative stress damages multiple cellular components including DNA, lipids, and proteins and has been linked to pathological alterations in NAFLD. Reactive oxygen species (ROS) attack polyunsaturated fatty acids and initiate lipid peroxidation within the cell, which results in the formation of aldehyde by-products such as MDA. Thus, MDA is widely used as a marker of lipid oxidation that reflects the level of oxidative stress. Study have found that the content of MDA which was increased obviously in NAFLD patients was positively related to the degree of inflammatory necrosis and fibrosis in liver tissue [32]. In our study we founded that the content of MDA both in NAFLD patients and cells model were increased as well as and the activity of SOD were decreased, it prompt that the imbalance of the level of oxidation and antioxidant play a important role in the formation of NAFLD. PGC-1a not only can regulate the induction of antioxidant defenses including SODs, catalase and GPx [33] but also can increase the expression of the metabolic sensor $\mathrm{NAD}^{+}$-dependent deacetylase sirtuin 3 (Sirt3), a key regulator of the mitochondrial antioxidant system [34]. We founded that the expression of PGC-1 $\alpha$ mRNA showed a negative correlation with the levels of triglyceride and the concentration of MDA as well as showed a positive correlation with the activity of SOD in L-02 cells, it means that PGC-1 $\alpha$ is closely related to the level of oxidative stress.

In view of the fact that insulin resistance plays a key role in the pathogenesis of NAFLD, improving insulin resistance and increasing insulin sensitivity may be a target in the treatment of NAFLD. Metformin and insulin sensitizing agents are the drugs that commonly used. Metformin appears to be both an anti-hyperglycemic drug and a therapeutic tool for the treatment of insulin resistance, in which it plays a pivotal role in depressing of fatty acid oxidation and treating the metabolic syndrome [35]. The activation of AMP-activated protein kinase (AMPK) may play a central role in metformin's actions [15]. AMPK is an important regulatory factor of energy metabolism in cells, it can not only regulates the oxidation of fatty acid and was also involved in the regulation of the insulin sensitivity. However, a recent study showed that AMPK deficiency did not abolish the effects of metformin on hepatic glucose production, indicating that the role of AMPK is dispensable [36]. The liver-protective mechanisms of metformin in NAFLD may be attributed to the down regulation of the inflammatory response and protection of mitochondrial function [37]. In this experiment, after the intervention of metformin, the level of triglyceride in the cells of drug group was lower than the cells in the model group. But the specific molecular mechanism that the metformin decreases the level of triglyceride in hepatocyte is unclear, We speculate that it is relate to the PGC- $1 \alpha$ which is involved in mitochondrial damage and the disorder of lipid metabolic.
In this experiment, undering the action of oleic acid the expression of PGC-1a and the activity of SOD in the cells of model group is decreased compared with the control group. We found that after the intervention of metformin, the expression of PGC-1 $\alpha$ and the activity of SOD was increased significantly in the cells of model groups. Through the experiment we come to the conclusion that Metformin can adjust the expression of PGC-1 $\alpha$ and the level of oxidative stress which can decrease the fat accumulation. Consistent with the results of our research, it had demonstrated that the expression of PGC-1a is reduced in skeletal muscle in vivo and also in the failing heart [38], and metformin increases the expression of PGC-1a protein [39]. Severeness of steatosis is associated with impaired PGC-1 $1 \alpha$ expression and reduced mitochondrial gene expression [40].

In conclusion, Metformin can adjust the expression of PGC-1 $1 a$ and the level of oxidative stress. The increment of mitochondria aftering the treatment of metformin would at least partially be expected to be due to the increased expression of PGC-1a. A previous study [22] demonstrated the expression of PGC-1 $1 \alpha$ can stimulate mitochondrial proliferation and increase the mtDNA copy number, Such a role of PGC-1 $\alpha$ for improving the mitochondrial capacity is one of the possible mechanisms for the metformin action.

\section{References}

1. Leng SX, Tian XP, Durso S, Lazarus G, Lu C, et al. (2008) The aging population and development of geriatrics in China. J Am Geriatr Soc 56: 571-573.

2. Adams LA, Lymp JF, St Sauver J, Sanderson SO, Lindor KD, et al. (2005) The natural history of nonalcoholic fatty liver disease: a population-based cohort study. Gastroenterology 129: 113-121.

3. Kawada N, Imanaka K, Kawaguchi T, Tamai C, Ishihara R, et al. (2009) Hepatocellular carcinoma arising from non-cirrhotic nonalcoholic steatohepatitis. J Gastroenterol 44: 1190-1194.

4. Jansen PL (2004) Non-alcoholic steatohepatitis. Eur J Gastroenterol Hepatol 16: $1079-1085$.

5. Bugianesi E, Leone N, Vanni E, Marchesini G, Brunello F, et al. (2002) Expanding the natural history of nonalcoholic steatohepatitis: from cryptogenic cirrhosis to hepatocellular carcinoma. Gastroenterology 123: 134-140.

6. Arslan N, Makay B (2010) Mean platelet volume in obese adolescents with nonalcoholic fatty liver disease. J Pediatr Endocrinol Metab 23: 807-813.

7. Aygun C, Kocaman O, Sahin T, Uraz S, Eminler AT, et al. (2008) Evaluation of metabolic syndrome frequency and carotidartery intima-media thickness as risk factors for atherosclerosis in patients with nonalcoholic fatty liver disease. Dig Dis Sci 53: 1352-1357.

8. Shoelson SE, Herrero L, Naaz A (2007) Obesity, inflammation, and insulin resistance. Gastroenterology 132: 2169-2180.

9. Martín-Domínguez V, González-Casas R, Mendoza-Jiménez-Ridruejo J García-Buey L, Moreno-Otero R (2013) Pathogenesis, diagnosis and treatment of non-alcoholic fatty liver disease. Rev Esp Enferm Dig 105: 409-420.

10. Loomba R, Lutchman G, Kleiner DE, Ricks M, Feld JJ, et al. (2009) Clinica trial: pilot study of metformin for the treatment of non-alcoholic steatohepatitis. Aliment Pharmacol Ther 29: 172-182.

11. Loomba R, Lutchman G, Kleiner DE, Ricks M, Feld JJ, et al. (2009) Clinica trial: pilot study of metformin for the treatment of non-alcoholic steatohepatitis. Aliment Pharmacol Ther 29: 172-182.

12. Scarpello JH, Howlett HC (2008) Metformin therapy and clinical uses. Diab Vasc Dis Res 5: 157-167.

13. Zang M, Zuccollo A, Hou X, Nagata D, Walsh K, et al. (2004) AMP-activated protein kinase is required for the lipid-lowering effect of metformin in insulinresistant human HepG2 cells. J Biol Chem 279: 47898-47905.

14. Yin W, Mu J, Birnbaum MJ (2003) Role of AMP-activated protein kinase in cyclic AMP-dependent lipolysis In 3T3-L1 adipocytes. J Biol Chem 278: 4307443080.

15. Zhou G, Myers R, Li Y, Chen Y, Shen X, et al. (2001) Role of AMP-activated protein kinase in mechanism of metformin action. J Clin Invest 108: 1167-1174. 
Citation: Jiang JH, Cheng J, Zhang B, Guan SX, Hou LI (2015) The Changes of the Expression of PGC-1a and the Level of Oxidative Stress in NAFLD as well as the Effects of Metformin on NAFLD. J Metabolic Synd 5: 193. doi:10.4172/2167-0943.1000193

Page 6 of 6

16. Miller RA, Birnbaum MJ (2010) An energetic tale of AMPK-independent effects of metformin. J Clin Invest 120: 2267-2270.

17. Grisouard J, Timper K, Radimerski TM, Frey DM, Peterli R, et al. (2010) Mechanisms of metformin action on glucose transport and metabolism in human adipocytes. Biochem Pharmacol 80: 1736-1745.

18. Kaser S, Ebenbichler CF, Tilg H (2010) Pharmacological and nonpharmacological treatment of non-alcoholic fatty liver disease. Int J Clin Pract 64: 968-983

19. Arany Z, He H, Lin J, Hoyer K, Handschin C, et al. (2005) Transcriptional coactivator PGC-1 alpha controls the energy state and contractile function of cardiac muscle. Cell Metab 1: 259-271.

20. Finck BN, Kelly DP (2006) PGC-1 coactivators: inducible regulators of energy metabolism in health and disease. J Clin Invest 116: 615-622.

21. St-Pierre J, Drori S, Uldry M, Silvaggi JM, Rhee J, et al. (2006) Suppression of reactive oxygen species and neurodegeneration by the PGC-1 transcriptional coactivators. Cell 127: 397-408.

22. Valle I, Alvarez-Barrientos A, Arza E, Lamas S, Monsalve M (2005) PGC1 alpha regulates the mitochondrial antioxidant defense system in vascular endothelial cells. Cardiovasc Res 66: 562-573.

23. Handschin C (2009) The biology of PGC-1 Ît and its therapeutic potential Trends Pharmacol Sci 30: 322-329.

24. Viollet B, Guigas B, Leclerc J, Hébrard S, Lantier L, et al. (2009) AMP-activated protein kinase in the regulation of hepatic energy metabolism: from physiology to therapeutic perspectives. Acta Physiol (Oxf) 196: 81-98.

25. Razavizade M, Jamali R, Arj A, Talari H (2012) Serum parameters predict the severity of ultrasonographic findings in non-alcoholic fatty liver disease. Hepatobiliary Pancreat Dis Int 11: 513-520.

26. Okamoto Y, Tanaka S, Haga Y (2002) Enhanced GLUT2 gene expression in an oleic acid-induced in vitro fatty liver model. Hepatol Res 23: 138-144.

27. Soyal S, Krempler F, Oberkofler H, Patsch W (2006) PGC-1alpha: a poten transcriptional cofactor involved in the pathogenesis of type 2 diabetes. Diabetologia 49: 1477-1488.

28. Handschin C, Spiegelman BM (2006) Peroxisome proliferator-activated receptor gamma coactivator 1 coactivators, energy homeostasis, and metabolism. Endocr Rev 27: 728-735.
29. Lin J, Handschin C, Spiegelman BM (2005) Metabolic control through the PGC1 family of transcription coactivators. Cell Metab 1: 361-370.

30. Estall J L, KahnM, CooperM P, Fisher FM, Wu MK, et al. (2009) Sensitivity of lipid metabolism and insulin signaling to genetic alterations in hepatic peroxisome proliferator-activated receptor-gamma coac-tivator-1 alpha expression. Diabetes 58: 1499-1508.

31. Koo SH, Satoh H, Herzig S, Lee CH, Hedrick S, et al. (2004) PGC-1 promotes insulin resistance in liver through PPAR-alpha-dependent induction of TRB-3. Nat Med 10: 530-534.

32. Yesilova Z, Yaman H, Oktenli C, Ozcan A, Uygun A, et al. (2005) Systemic markers of lipid peroxidation and antioxidants in patients with nonalcoholic Fatty liver disease. Am J Gastroenterol 100: 850-855.

33. St-Pierre J, Drori S, Uldry M, Silvaggi JM, Rhee J, et al. (2006) Suppression of reactive oxygen species and neurodegeneration by the PGC-1 transcriptional coactivators. Cell 127: 397-408.

34. Kong X, Wang R, Xue Y, Liu X, Zhang H, et al. (2010) Sirtuin 3, a new targe of PGC-1alpha, plays an important role in the suppression of ROS and mitochondrial biogenesis. PLoS One 5: e11707.

35. Muntoni S (1999) Metformin and fatty acids. Diabetes Care 22: 179-180.

36. Foretz M, Hébrard S, Leclerc J, Zarrinpashneh E, Soty M, et al. (2010) Metformin inhibit $s$ hepatic gluconeogenesis in mice independently of the LKB1/AMPK pathway via a decrease in hepatic energy state. J Clin Invest 120: 2355-2369.

37. Huang Y, Fu JF, Shi HB, Liu LR (2011) [Metformin prevents non-alcoholic fatty liver disease in rats: role of phospholipase A2/lysophosphatidylcholine lipoapoptosis pathway in hepatocytes]. Zhonghua Er Ke Za Zhi 49: 139-145.

38. Huss JM, Kelly DP (2005) Mitochondrial energy metabolism in heart failure: a question of balance. J Clin Invest 115: 547-555.

39. Suwa M, Egashira T, Nakano H, Sasaki H, Kumagai S (2006) Metformin increases the PGC-1alpha protein and oxidative enzyme activities possibly via AMPK phosphorylation in skeletal muscle in vivo. J Appl Physiol (1985) 101 1685-1692.

40. Lin J, Handschin C, Spiegelman BM (2005) Metabolic control through the PGC1 family of transcription coactivators. Cell Metab 1: 361-370. 